\section{TEACHING ENGLISH THE STUDENT-ACCOMMODATING WAY}

\section{Peansiri E. Vongvipanond ${ }^{1}$}

\section{Introduction}

This paper is a description of the management of an English Language Teaching and Learning Program at Dhurakij Pundit University (DPU), a Thai private university established in 1968. The term "learning" is added to the title of the program deliberately in order to emphasize, at least to members of our own teaching team, that our students' learning achievement is as critical a success factor as our own teaching. The acronym "ELT\&L" has been adopted among us to remind ourselves that unless our students are learning or have learned something, we fail in our work

The term "management" is used in this paper to reflect our perception of our work as a business operation. We look at our work as a process in which we turn our input learners into valuable output, competent users of English. As business operators, we, the teachers as well as the program administrators, are held accountable by all stake holders: our students, their parents or guardians who support them, the university administration and the general public, whose trust and confidence we are trying to win. Students, regardless of their learning styles and the degree of their learning commitment, want us to do o ur w ork in a way that b enefits them, however one takes the word

${ }^{1}$ Ph.D., Director, Language Institute, Dhurakij Pundit University "benefit" to mean. Parents, who have to shoulder the financial and emotional burden, expect their children to succeed in English courses and to be competent enough in the language to secure their future career. The university administration expects us to succeed in our endeavor so that our success can add an edge to its competitiveness in order to attract more motivated and more committed students. The general public is divided between those who overlook or dismiss us as an inferior institution and those who closely scrutinize us. We need to succeed in order to attract the attention of the former and earn the trust of the latter. In short, not unlike a business enterprise, we cannot keep teaching and doing our best without monitoring the quality of our work and evaluating our performance.

Five topics are included in this paper. First is a description of the goals of the program. Second are the profiles of our learners. This is followed by the solutions we have adopted in our ELT\&L Program. Next we present a discussion of what goes on in a classroom because this is obviously the most critical success factor in an assessment of our work. The paper concludes with a discussion of the problem in evaluating our program.

\section{Goals}

As in any business enterprise, we need to set and clearly define our goals. Fortunately, we do not have to identify the goals ourselves, as The English Language Curriculum Development Task Force was appointed by the Ministry of University Affairs (MUA) in 2001 to e stablish a s et of goals and standards against which a learning and teaching evaluation can be made. After many workshops, assisted by experts provided by the United States 
Information Service, the Task force completed their proposal, which was proposed to and granted support by the Conference of University Presidents. The proposal consists of goals, standards and samples of behavioral descriptors to guide ELT instructors in the evaluation process. Quoted here are the goals and standards proposed by the Task Force.

\section{Goal 1: To use English to communicate in social settings both inside and outside the university:}

Standard 1: Students will use spoken and written English for personal statement, and for enjoyment and enrichment.

Standard 2: Students will use spoken and written English to participate appropriately in social interaction.

Standard 3: Students will recognize and understand cultural differences.

Standard 4: Students will use appropriate learning strategies to extend their communicative competence.

Goal 2: To use English to help achieve personal and academic goals and to promote life-long learning:

Standard 1: Students will use English to access and process information and to construct knowledge in both spoken and written forms.

Standard 2: Students will use English to participate in academic contexts.

Standard 3: Students will use appropriate learning strategies to acquire, construct, and apply academic knowledge and to develop critical thinking skills.

These goals were formulated as DPU was re-engineering its English language program and the decision was made to adopt these goals. In addition, we also added a third goal for
DPU, which is the ability to use English in the work place for career purposes. The following is our Goal 3. 


\section{Goal 3: To use English to achieve career goals}

Standards1: Students will use English in their search for a career of their choice

Standard 2: Students will use English for interaction with others in their workplace

With these goals adopted, the English language component in most DPU curricula carries a minimum of six credits of Foundation English and a minimum of six credits of English for Specific or Career $\mathrm{P}$ urposes. S ome p rograms such as the English Major Program and the Hotel Study and Tourism Program require more credits of English. The goals described above are adhered to both in what Richards and Rodgers (2001) call the design and the procedure components of the program. That is, the goals are always kept in mind when we design our curricula and course syllabi and when we try to materialize these designs in our classroom teaching procedure.

\section{Learner profile at DPU}

Who are our students? Superficially, they are not very different from the majority of students in English language classrooms in most Thai universities. They seem to have the symptoms of learners mentioned in the questionnaire Willis (1996) used to support her Task-based Learning Technique, namely, that they leave secondary school unable to communicate in English and go on making the same errors even after being corrected many times. However, a more detailed analysis is needed before we can decide what and how to teach them. This is the view we have of our students, whom we believe are not unique in any way. We present these profiles simply as a preliminary to the description of our ELT\&L Program in the next section.
First, most of our learners come to us, a private university, in some ways psychologically traumatized. They have failed to gain entrance into a state university. The degree of trauma may vary among them, depending on how much they have invested in their own secondary school education and their preparation for the rigorous and highly competitive screening process. To a certain extent, they seem to have lost their sense of selfconfidence and self-worth. Many may have also been mentally drained and exhausted after many previous attempts to attend state or private universities. In short, many of our students come to us with low self-esteem, a negative attitude towards their future university $\mathrm{c}$ areer and doubt particularly with regard to their ability to succeed in learning English. It is plain and clear that these affective and attitudinal tendencies negatively affect the way our students look at the English courses they are required to take. What do we do to restore their self-confidence and their motivation and enthusiasm to succeed in learning English?

Second, our students come with disparate levels of English proficiency. A "mixed class" takes on a new meaning when we look at our students. We have students who come to us with secondary school certificates as well as vocational school certificates, which are equivalent to an associate university degree. Even within these two groups, the levels of English are still quite disparate, reflecting their varied 
English language learning history. With the educational reforms still to be stabilized, this situation does not seem to get better and this poses another challenge to us. How do we teach so that the better students can build on what they already have and go forward while the weaker students feel encouraged, supported and assisted?

Third, our students come with different perceptions of the part they have to play in their own English language learning. Most are still used to being spoon-fed and told what to do. Many still need to be coerced to learn English. A few would rather be given passing grades and forget all about learning English. Besides adding an " $\mathrm{L}$ " to the title of our program, what do we do to make our students play a more pro-active role in their own learning?

Fourth, an increasing number of our students seem to be coming from a different socio-cultural backgrounds than their teachers, in that they are used to the "multimedia world" and the immediate feedback in their interaction with the computers in both work and play. Unconsciously, they demand that the English language lessons be conducted in a multimedia environment, through interactive delivery and with immediate feedback. They can easily lose interest if made to sit inactively in rows listening to their teachers' presentations and doing their language exercises on printed handouts. What do we do to make our teachers appreciate this fact and reengineer the way we teach our students?

\section{ELT\&L Program at DPU}

The ELT\& L Program at DPU has been designed with both the goals we have adopted and the characteristics of our input learners in mind. We w ould like to call it a student-accommodating program because we are trying to accommodate all the problematic features of our learners as presented in section 3. Readers should be cautioned that this is a report of w ork in progress and we have yet to perfect our methodology and to achieve our teaching goals and help our students achieve their learning goals.

\section{Teaching Approaches}

According to the goals we have set for ourselves, we cannot help but adopt the Communicative Approach in our teaching. We a im a t e nabling a nd e mpowering our students to "use" English and to "learn" language rules simply as monitoring or editing mechanism (Krashen 1981). It is undeniable that this is a Herculean task for all English language teachers in Thailand, an officially monolingual country where one can still get by in life with no English unless one hopes to have better career or job opportunities. Motivation to succeed in learning English is, as a consequence, rather feeble. Despite the fact that there are ever more English language cable TV channels, more English internet services and more publications in English, for most learners the only exposure to English is still in the classroom. The same is true with the use of English. Problems with the exposure, use and motivation components lead many teachers to resort to instruction (Willis 1996: 10-17), which is antithetical to the Communicative Approach.

To remedy this situation, role-playing is usually used in teaching speaking and writing. Students are taught to consider the contextual factors such as purpose, participants, place, time, etc. before they speak or write. Their learning performance is evaluated in a "real" speaking test, in 
which a pair or a group is given an interactional situation and the roles to play. Two instructors are assigned to monitor and evaluate each pair or group of students. The sand trap here is that students often try to prepare and memorize conversation scripts instead of trying to play the roles given. Recorded tapes and CD's of native speakers' oral performance are also used both in class and in the computer labs to teach listening. Students are also encouraged to read authentic texts in newspapers, magazines, books and websites. There are also computerized reading exercises available for them.

Even with all these attempts on the part of the teachers, we have not won this ELT yet and the battle is still going on.

\section{Regaining students' self-esteem and self-confidence}

Self-esteem and self-confidence are necessary ingredients in a person's success. It takes extra care and attention on the part of the teachers to help learners regain these feelings. Classes cannot be too large. An English language class at DPU averages at 40 students, while English major classes can be much smaller. This allows teachers to be closer and to get to know their learners better. It also allows for individual learning activities a s well as pair work and group work.

In addition, every instructor at DPU is required to set aside six hours for student consultation service. These consultation hours are considered a standard service for students a nd must be a nnounced publicly according to the ISO quality assurance policy of the university. As for the English language P rogram, a dditional c onsultants, both Thai and native speaker, are also available everyday in the Consultation and Student Help Center, nicknamed the Glass Room by the students.

Furthermore, at DPU, the student-centered approach to teaching is taken seriously the university has set up a system in which instructors can apply for a Certified Teaching Award. In addition to the certification of the quality of teaching, successful applicants are also given a substantial monthly bonus as a reward. Being student-centered in the way one teaches is a major awarding criteria. In the first semester of the academic year 2004, five out of the six awardees were members of the Language Institute.

Formative evaluation is another strategy to boost students' confidence. Most formative test tasks are intended to monitor students' progress and success. They are not meant to spot students' errors or mistakes. These formative tests also keep students aware of their own performance and efforts in the courses. A scaffolding scheme (Bruner 1966) can also be adopted be the teachers, with explicit criteria, to help students who have difficulty despite their hard work.

Helping students to regain their sense of self-worth and self confidence is perhaps area where we succeed the most, if students' e valuation $\mathrm{c}$ an be considered an indicator. The average score of almost all English language teachers at DPU is at least four out of five.

\section{Placement test and grouping of students}

The controversy remains whether we should group students with similar language proficiency together or we should have a mixed group. Both sides seem to have good reasons for their 
choice. At DPU, students are given a placement test upon entering the ELT\&L program, usually in the first semester of their first year. The scores are used to group students according to their levels of English. Our justification is first and foremost the gap between the strong and the weak students. We wish to provide extra assistance to weaker students and push the stronger students further. The same course syllabus is used for all students registered in the same course. The same course books are also used. However, teachers can adapt their lesson plans and add supplementary activities and materials to suit their students. They can also give students extra assignments, provided that they have fulfilled all the requirements in the master course syllabus.

Students are regrouped after every final exam at the end of the semester, so that they always find new friends and new teachers in all their English courses.

\section{SALLC and pro-active learners}

A self access language learning center, or SALLC, was set up at the same time as the Language Institute. Its main objective is to help students develop more productive learning habits. Students are trained to extend their learning beyond class time and outside of their own classroom. A review of students' SALLC activities in the past five years can be an indication of the progress being made. Students' SALLC activities can be divided into three phases or levels: the required learning, the guided learning and the independent learning. When it was first established, The main focus was habit formation. All students were required to make a number of visits to work in SALLC. SALLC activities were assigned by the teachers with marks given as rewards. A SALLC stamp was affixed in the students' SALLC book for every visit the students made to SALLC and every assignment completed. Not much learning was taking place. Students were concerned more with getting enough stamps. Still, they have developed good learning habit. Going to work in SALLC has become part of the routine of students' life at DPU. The second phase is more ambitious. Students are now assigned SALLC work, which prepares them for the follow-up work in class. The SALLC stamp is losing its importance and copying from each other just to get their books stamped is becoming a meaningless activity. The installation of computerized learning systems with an inherent test management system in SALLC makes it easier to monitor students' SALLC activities. The second phase of SALLC is still going on. We are now encouraging students to graduate to the third phase. At the moment, it is possible mostly with students in the English Major Program and very few forward-looking students in the General English and the English for Specific Purposes Programs. These students work with their teachers to design their own SALLC program. The reward they receive comes from their own learning achievement more than compliments and marks from their teacher-consultants.

\section{Entering the interactive multimedia learning era}

As pointed out in section 2, students are acquainted with the use of computers in almost all spheres of their life, especially in entertainment. They have become used to multimedia computer games and shows. Not only that these are more attractive with colors and sounds but learners can 
obtain an i mmediate feedback and result, for example, whether they win or lose and how many marks they make. The convenient use of the systems and the user's ability to pick and choose add to their attraction. The first computerized learning system in DPU was entitled "ELLIS". It was used primarily by students in the English major program for exposure to real language and for improving their own speaking and reading skills. When SALLC was set up, more computerized learning systems were acquired. And more systems are being added. In addition to extended learning in SALLC, computerized lessons are also being used now as teaching and learning materials for entire courses both in the General English and the English for Specific Purposes Programs. The number of $c$ omputers in S ALLC $h$ as increased to more than eight hundred and so has the number of students' visits to SALLC learners. During peak hours, students have to wait in line for services. The situation is entirely different from what we saw during the early years of SALLC.

\section{The classrooms}

It is what actually goes on in the classroom which determines if an educational program succeeds or fails. This is true also in the case of English language teaching. It does not matter how well-researched or how theoretically sound a program is but it is how the teachers teach that decides how much the learners learn.

At DPU, the ELT\&L Team consists of 84 full-time instructors. We avoid hiring parttime teachers because most cannot dedicate their time for student consultation. Taking into consideration the characteristics of our students described in section 3 , the following guidelines are adopted in the teaching of English at the Language Institute:

(1) The course syllabus and a tentative lesson plan must be made available to all students registered for the course in the first two weeks, according to the ISO directives of the university. The objectives of the course, the scope of content and skills to be covered and the evaluation measures must be clearly stated. This is the minimum requirement.

(2) Teachers who are assigned to teach the same course form a team and meet to decide the master course syllabus, the scope of content and skills, the evaluation measures, the writing of exam papers and the required SALLC activities.

(3) Individual teachers, however, have the autonomy to teach their classes the way they see fit as long as they fulfill the minimum requirement stated in the course syllabus. Teachers are urged to produce appropriate supplementary materials for their own students, who are grouped according to their levels of proficiency. A small budget for this purpose is allocated to all teachers.

(4) Extended learning activities are recommended for all classes, either in SALLC, in other Internet labs or in the library.

(5) There must be both formative and summative evaluations. Students must be informed of the results of 
the formative evaluations so they can plan their study accordingly.

(6) In c lass, the time for s tudent talk must be longer than that of teacher talk.

(7) The integrated-skill approach is adopted, and there should be a balance between productive language skills (speaking and writing) and receptive language skills (reading and listening).

(8) Emphasis is put on exposure and use of English and not on instruction, so English is to be the language of the classrooms and Thai should be kept to the minimum, i.e., only when an explanation in English will be too time-consuming.

(9) Active learning through various types of activities is prescribed. Activities such as simulated situations, role-playing, and taskbased projects are highly recommended.

Of these nine guidelines, two are the most difficult to follow. These are guidelines (8) and (9). The concepts exposure, use, and instruction are adopted from Willis's list of conditions for language learning (1996:11). According to her, exposure, use and motivation are the "essential" conditions while instruction is recommended as a desirable condition. English needs to be used as medium of instruction at the university level because it is here that students can see the relevance of English to their university career. It is here also that students can be motivated to try and learn the language. When the teachers give in to the students' demand for an easy way out and speak Thai, they are stunting their students' growth and killing their motivation.

Guideline (9) requires that the teachers be resourceful, hard-working and open to new ideas. Nowadays, there are numerous web sites which offer free ideas, and even free materials, for teaching English at all levels of difficulty. Teaching through activities, instead of lecturing, requires good planning and preparation. Despite undeniable evidence that students enjoy learning through a variety of activities and tasks, a few teachers still lecture and give their students grammar exercises and multiple-choice questions on paper. Occasional complaints are filed by students who are used to activity-filled classes but are assigned to study with a new teacher who prefer to lecture about grammar rules.

The failure to follow guidelines (8) and (9) often results from the fact that teachers tend to teach the way they were taught in the past. The promotion of the Communicative Language Teaching (CLT) approach started in Thailand about 20 years ago. Younger instructors tend to have been taught English within this approach so they are more inclined to teach communicatively. To remedy the situation, teachers at the Language Institute are now encouraged to conduct classroom action research to find out how to enable their students to learn English better. It is likely that many of our current students have experienced CLT classes of English in secondary schools and they expect similar teaching methods. Teachers are urged to start with a simple action research like those published in Richards (1998) or with a collaborative project as discussed in Burns (1999). 
Another plan to help teachers teach communicatively and in English is to provide them with a short study trip to an English speaking country so that they can have an opportunity to make English their second language and observe how English is taught in that country.

\section{Conclusion}

The best conclusion for this paper should be an evaluation of our ELT\&L program, in which we can present our success, supported by statistical figures, and our failure, equipped with proposed plans to remedy the problems. This is wishful thinking. It is difficult to assess an ELT program. In order to have a proper assessment tools and processes, we have to begin with a re-examination of the two goals, officially recognized and endorsed by the Office of the Commission on Higher Education, and the third goal added by our team at DPU. Are the goals realistic and achievable by Thai students in monolingual secondary schools and universities? The implication of the goals is that our students should acquire a competence of a near-second-language speaker of English. Their ability to use English needs not be equivalent to that of students in Singapore and India but they ought to be competent in English enough to benefit from the language in their student career and their future career. Next we can look at the instruction. As long as English is taught in universities, and schools, as a separate subject and is not integrated into the teaching of other content subjects, students will have difficulty justifying why they should investment their time and energy in the learning of English, which may be w orth $6-12$ credits. With the achievability of the goals in doubt and the learners' motivation in suspense, it is almost impossible to assess the success or failure of an English language program.

Teaching English in a monolingual context like Thailand is similar to walking up a down staircase during rush hours. It is an uphill struggle and most other people are heading towards the opposite direction. To console o urselves that we will e ventually reach the top of the stairs if we keep walking and wading in the crowds is futile. Imagine the time and the energy we waste, or have already wasted, in this feat. Would it $n$ ot be better, if we were to redesign the stair traffic by making it a twoway passage with a keep-left rule? How does this translate into our ELT work? We have to amend our education system and make English a part of the curriculum at all levels. English must be used in all subjects beginning from elementary schools all the way up to universities. It should be learned also in the contentbased manner (Krahnke 1987:65), and only as a separate subject, worth 3-12 credits. We can start with external reading assignments at the elementary school level and gradually move up to research using printed as well as computerized materials at the university level. Reading is a convenient way to be exposed to the use of the language as well as to learn language forms at the lexical, the syntactical and even the textual levels. With the availability of more computers in schools, at home and in Internet cafes, exposure to oral communication in English, also in the content-based manner, i.e. as assignments in content subjects, can be another significant push. If these recommendations were to be adopted, ELT teachers would be left to concentrate more on the interactive skills of writing and speaking. 
In actuality, this is what is happening in the bi-lingual education programs in elementary and secondary schools now. In trying to solve one educational problem in this manner, we manage to cause another problem, a socio-economic one. The gap between the "have" and the "have-not" will be further widened.

To conclude this conclusion, we would like to say that it takes all stake holders, including the government and the Ministry of Education, to re-engineer the ELT policy and to re-design the stair traffic. It is only when we make English meaningful enough in our learner' student $c$ areer and their life career that they will be willing to invest their time and energy learning English.

\section{References}

Bruner, Jerome. 1966. Towards a Theory of Instruction. Cambridge, Massachusettes: Harvard University Press.

Burns, Anne. 1999. Collaborative Action Research for English Language Teachers. Cambridge: Cambridge University Press.

Krashen, S.D. 1981. Second Language Acquisition and Second Language Learning. Oxford: Pergamon.

Richards, J.C. 1998. Teaching in Action: Case Studies from Second Language Classrooms. TESOL, Inc.

Richards, J.C. and Rodgers, T.S. 2001. Approaches and Methods in Language Teaching. Cambridge University Press.

Willis; Jane. 1996. A Framework for Task-based Learning. Addison, Wesley Longman Ltd. 